Article

\title{
Diurnal Variability of Persistent Organic Pollutants in the Atmosphere over the Remote Southern Atlantic Ocean
}

\author{
Rosalinda Gioia $^{1,2, *}$, Matthew MacLeod ${ }^{3, \dagger}$, Javier Castro-Jiménez ${ }^{4}$, Luca Nizzetto ${ }^{1,5}$, \\ Jordi Dachs ${ }^{4}$, Rainer Lohmann ${ }^{6}$ and Kevin C. Jones ${ }^{1}$ \\ 1 Lancaster Environment Centre, Lancaster University, Lancaster LA1 4YQ, UK; \\ E-Mails: luca.nizzetto@niva.no (L.N.); k.c.jones@lancaster.ac.uk (K.C.J.) \\ 2 The Centre for Environment, Fisheries and Aquaculture Science, Cefas Lowestoft Laboratory, \\ Pakefield Road, Lowestoft, Suffolk NR33 0HT, UK \\ 3 Swiss Federal Institute of Technology, CH-8093 Zurich, Switzerland; \\ E-Mail: matthew.macleod@itm.su.se
}

4 Department of Environmental Chemistry, CSIC-IDAEA, Jordi Girona 18-24, E-08034 Barcelona, Spain; E-Mails: jcjqam@idaea.csic.es (J.C.-J.); jordi.dachs@idaea.csic.es (J.D.)

5 Norwegian Institute for Water Research, Gaustadalleen 21, NO-0349 Oslo, Norway

6 Graduate School of Oceanography, University of Rhode Island, Narragansett, RI 02882, USA;

E-Mail: Lohmann@gso.uri.edu

$\dagger$ Current Affiliation: Department of Applied Environmental Science, Stockholm University, SE-11418 Stockholm, Sweden.

* Author to whom correspondence should be addressed; E-Mail: rosalinda.gioia@cefas.co.uk; Tel.: +44-1502-524-393.

Received: 15 May 2014; in revised form: 14 July 2014 / Accepted: 21 July 2014 /

Published: 22 August 2014

\begin{abstract}
A diel (24-h) cycle with daytime atmospheric concentrations higher than nighttime concentrations by a factor of 1.5-3 was observed for several low molecular weight polychlorinated biphenyls (PCBs) and polycyclic aromatic hydrocarbons (PAHs) in remote areas of the tropical South Atlantic during a cruise in October-November 2005. In contrast, high molecular weight PCBs and PAHs did not display diurnal variability. A model which has successfully explained diel variability of persistent organic pollutants (POPs) over land could not reproduce the observed diel cycle by considering variability in temperature, atmospheric $\mathrm{OH}$ radical concentrations, atmospheric boundary layer height and wind speed as causal factors. We used the model to conduct two bounding scenarios to
\end{abstract}


explore the possibility that phytoplankton biomass turn-over in the surface ocean drives the observed variability in air concentrations. The model could only qualitatively reproduce the field observations of diel variability for low chlorinated PCB congeners when the ocean acts as a source of pollutants to the atmosphere, and when variability in biomass drives variability in the capacity of the surface ocean.

Keywords: persistent organic pollutants (POPs); diurnal cycle; polychlorinated biphenyls (PCBs); polycyclic aromatic hydrocarbons (PAHs); South Atlantic

\section{Introduction}

Exchange between the lower atmosphere and surface ocean water is an important process in the transfer of POPs from the atmosphere to the deep ocean [1]. Air-water gas exchange is the major depositional process of many classes of POPs such as polychlorinated biphenyls (PCBs) and polycyclic aromatic hydrocarbons (PAHs) to the ocean surface [2]. Many factors can influence the equilibrium conditions of the air-ocean system; one of these is the phytoplankton biomass [3]. Air-water exchange and partitioning to/uptake by phytoplankton act as coupled processes in aquatic environments [4]. Once PCBs are in the dissolved phase in water, they can sorb to particles and organisms such as phytoplankton, and can be removed from the surface waters and delivered to the deep ocean along with sinking particles. Thus, phytoplankton may affect the dissolved concentration of pollutants in water and consequently their exchange between oceans and the atmosphere [3]. Water column biogeochemistry has already been shown to affect the atmospheric residence times and "grasshopping" by atmosphere-ocean exchange [5]. However, so far, it has not been shown that biogeochemistry can drive re-volatilization at short scales such as that observed diurnally.

Jaward et al. [6,7] reported a diurnal variability (diel cycle) for low molecular weight PCB congeners and some of the more volatile PAHs (phenanthrene, 1-methylphenanthrene and fluoranthene), with daytime concentrations in air higher than the night time concentrations typically by a factor of 1.5-2.5 from $1^{\circ} \mathrm{S}$ to $32^{\circ} \mathrm{S}$ in the Atlantic. No cycle was observed for the less volatile PCB congeners and PAHs and other compounds, including hexachlorocyclohexanes (HCHs) and hexachlorobenzene (HCB). This was the first time that such a diel cycle had been reported over the open ocean. Diel cycles had previously been observed in several studies on land (e.g., [8-14]); however, high daytime concentrations were usually associated with high daytime temperatures, which were not observed in the cycle over the ocean. Jaward et al. [6] hypothesized that interactions between plankton and the dissolved phase may play a role in their observations, but stated that further measurement data were needed to evaluate this hypothesis.

In this study diel variability of experimentally measured PCB and PAH concentrations in air from samples collected in the South Atlantic on board the $R V$ Polarstern in October 2005 is discussed [15,16]. In addition, an existing model [17] is adapted to conduct a bounding analysis of possible drivers of diurnal variability in remote marine environments which used forcing functions as inputs to the model for atmospheric temperature, mixing heights, wind speed, $\mathrm{OH}$ degradation and ocean biomass as described 
elsewhere [17]. Model scenarios provide first estimates of the magnitude of variability in phytoplankton biomass over a diel period that is required to drive the observed atmospheric diurnal variation.

\section{Methodology}

\subsection{Sampling and Chemical Analysis}

Air samples were collected on the $R V$ Polarstern during scientific cruises from Germany to Cape Town, South Africa, using published procedures. Details of the air sampling and analytical procedures have been described elsewhere [15,16]. Briefly, twelve hours integrated air samples were collected with an average volume of $150 \mathrm{~m}^{3}$. Both particulate and gas-phase were captured on a glass fiber filter (GFF) and polyurethane foam (PUF), respectively. High volume air samplers were operated in "good conditions" either when the ship was steaming or, if stationary, when the relative wind direction was between $0^{\circ}-90^{\circ}$ and $270^{\circ}-0^{\circ}$ and the wind speed greater than $4 \mathrm{~m} / \mathrm{s}$, to minimize interference from any potential ship contamination. Only a limited number of $12 \mathrm{~h}$ dissolved phase water samples were available. Large volumes of water (600-1000 L) and high flow rates are needed to be able to detect these pollutants in the seawater. Due to restrictions in the sampling media (small XAD-2 column and small filter), it was only possible to operate in a very low and narrow range of flow rate to ensure that the water had enough time to come into contact with the XAD-2 resin and that the filter did not clog or break. All samples were handled and extracted in a dedicated clean laboratory at Lancaster University, which has filtered, charcoal-stripped air and positive pressure conditions. For PCBs, each air (gas + particle) and water sample was spiked with a recovery standard of ${ }^{13} \mathrm{C}_{12}$-labeled PCB congeners $\left({ }^{13} \mathrm{C}_{12}\right.$ PCB $\left.28,52,101,138,153,180\right)$. Air samples were individually extracted in a Buchi extraction unit for $18 \mathrm{~h}$ with hexane, while water samples (XAD) were liquid-liquid extracted with $\mathrm{MeOH}$ followed by dichloromethane (DCM). Samples were purified using a multilayer $20 \mathrm{~mm}$ id acid silica column and a gel permeation columns containing $6 \mathrm{~g}$ of Biobeads SX 3 and concentrated to $100 \mu \mathrm{L}$. For PAHs, samples were Soxhlet-extracted for $12 \mathrm{~h}$ using $n$-hexane. Extracts were eluted in glass columns (9 mm i.d.) filled with $1 \mathrm{~g}$ of alumina, $2 \mathrm{~g}$ of silica gel, and $1 \mathrm{~g}$ of sodium sulfate (baked at $450{ }^{\circ} \mathrm{C}$ overnight). The extract was concentrated and immediately rediluted in $100 \mu \mathrm{L}$ of acetonitrile.

\subsection{Meteorological Data and Back Trajectories}

Meteorological data were collected from an online management system that collects nautical and scientific parameters from measuring devices installed on the vessel (PODAS-The POlarstern DAta System). Air and water temperature, wind speed and wind direction were obtained from the system every $5 \mathrm{~min}$. In addition, NOAA's HYSPLIT model and the NCEP/NCAR Global Reanalysis dataset were used to calculate back trajectories and atmospheric mixing height. Back trajectories were calculated for 7 days with $1 \mathrm{~h}$ steps at 00:00 coordinated universal time (UTC) at $500 \mathrm{~m}$ above sea. The trajectories showed air arriving at the samplers in the southern Ocean had crossed the Atlantic Ocean for at least 7 days prior to being sampled. 


\section{Results and Discussion}

\subsection{Diel Variability of PCBs and PAHs in Air}

Latitudinal trends of PCB and PAH concentrations during the whole cruise transect are reported elsewhere $[15,16]$. Proximity to land or air mass origin influences the highest/lowest concentration of these compounds during the cruise. However, in some areas concentrations appear to be controlled by different factors. This is apparent in the most remote samples of the South Atlantic Ocean, where the lowest PCB and PAH concentrations were observed, with average $\Sigma_{29} \mathrm{PCB}$ and $\Sigma_{13} \mathrm{PAH}$ concentrations of $18 \mathrm{pg} \cdot \mathrm{m}^{-3}$ and $180 \mathrm{pg} \cdot \mathrm{m}^{-3}$ respectively. Here a diel cycle of PCBs and PAHs was observed (see Figure 1). Daytime concentrations in air were higher than night time levels for the more volatile PCB congeners (PCB 28, 52 and 90/101) and PAHs (fluoranthene and phenanthrene) from $3^{\circ} \mathrm{N}$ to $12^{\circ} \mathrm{S}$ and from the equator to $27^{\circ} \mathrm{S}$ respectively (see Tables S1 and S2). Day time concentrations were higher than night time concentrations by a factor of 2-3 for the more volatile compounds and by a factor of 1.5-2 for the less volatile compounds (see Figure 1). These observations are consistent with data from Jaward et al. [6,7] who reported a diel cycle where day time concentrations were higher than night time concentrations by a factor of 1.5-2.5 for selected PCB congeners (PCB 28 and 52) and PAHs (phenanthrene, 1-methylphenanthrene and fluoranthene) from $1^{\circ} \mathrm{S}$ to $32^{\circ} \mathrm{S}$. In both cruises the diel PCB cycle was only observed in remote areas of the ocean from the equator to the South Atlantic. Jaward et al. [6,7] observed it along a more extended area $\left(1^{\circ} \mathrm{S}-32^{\circ} \mathrm{S}\right)$ for both PCBs and PAHs. The datasets were obtained on different ships ( $R V$ Pelagia and $R V$ Polarstern) and in different seasons (summer in references [6,7] and spring in this study). However, the differences in concentrations between day and night were very similar in both studies, and in both studies the diel variation was only observed for the lighter POPs and in parts of the Southern Ocean.

Figure 1. Diurnal trends in the Southern Ocean. (a) shows the diurnal cycle for selected polychlorinated biphenyls (PCB) congeners between $3^{\circ} \mathrm{N}$ and $27^{\circ} \mathrm{S}$; (b) shows the diurnal cycle for selected polycyclic aromatic hydrocarbons (PAHs) compounds between the $0^{\circ} \mathrm{S}$ and $25^{\circ} \mathrm{S} . \mathrm{D}=$ daytime samples. Missing samples for PAHs are due to sampler break down.

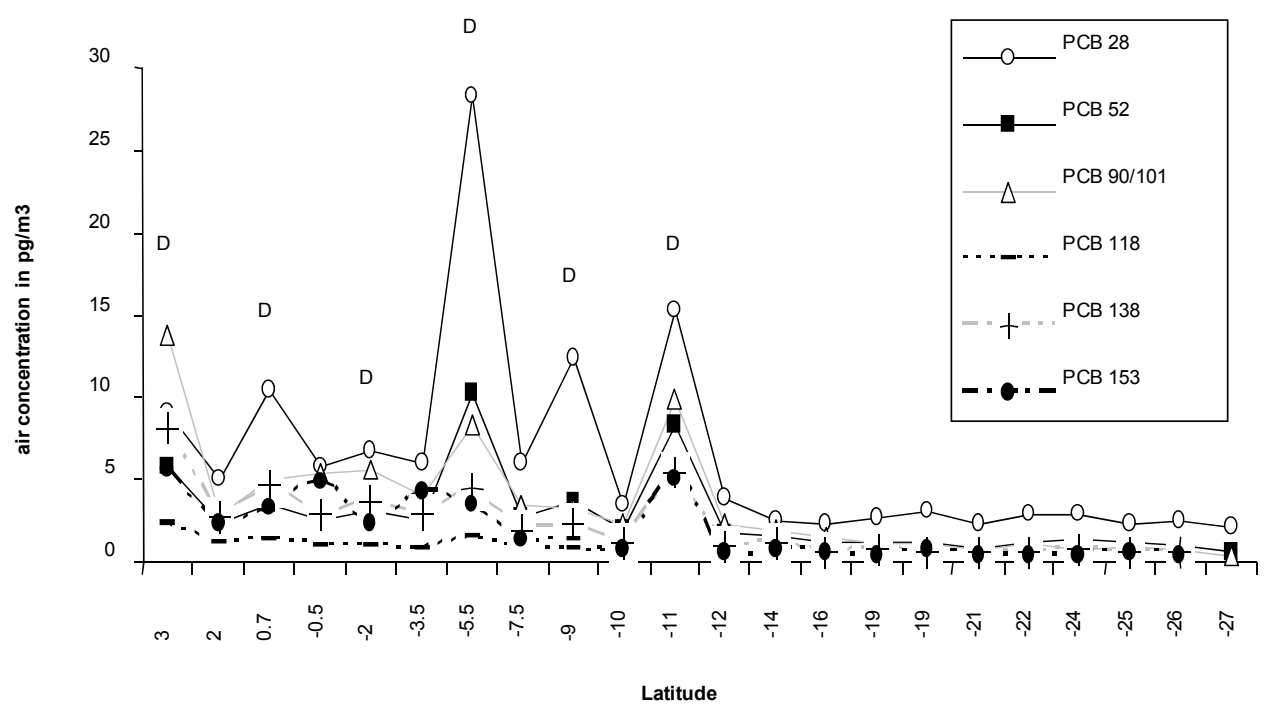

(a) 
Figure 1. Cont.

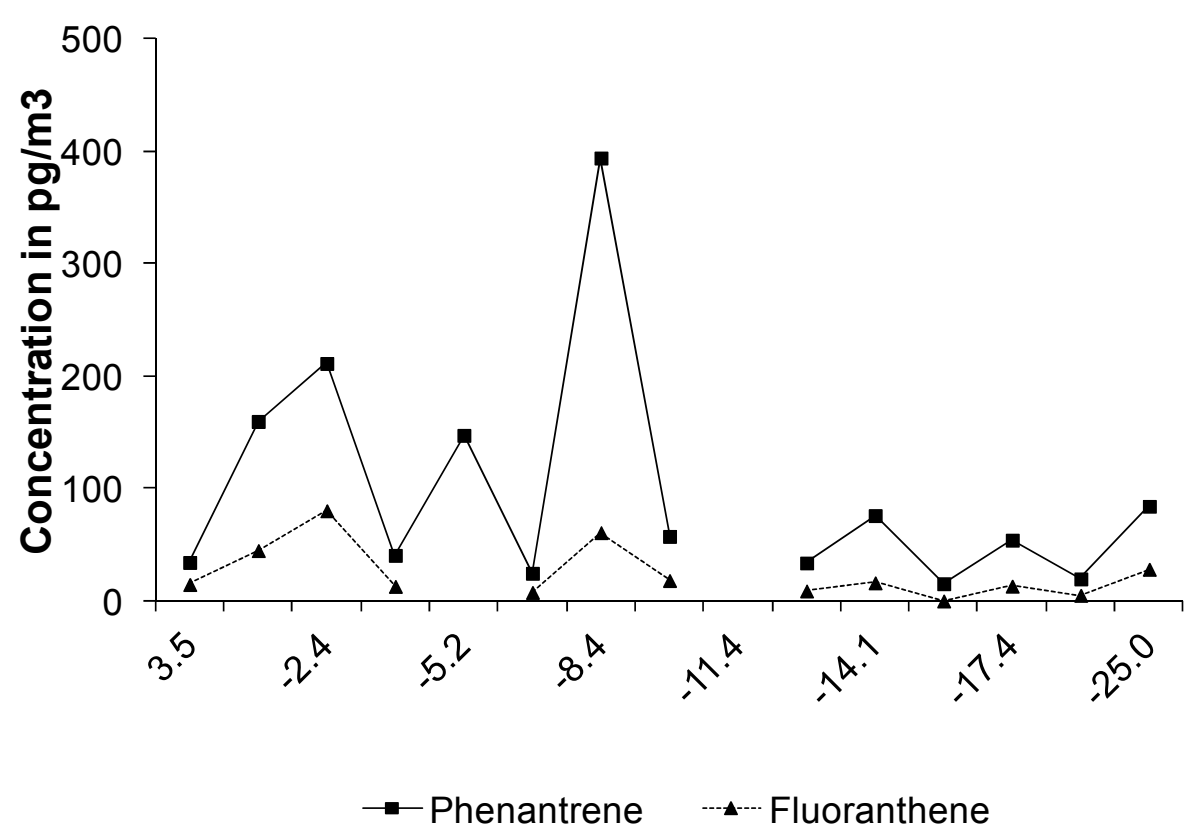

(b)

\subsection{Diel Variability of PCBs and PAHs in the Dissolved Phase}

Twelve hours seawater samples from the equator to 4-S were collected in the area where the diel cycle of POPs in the atmosphere had been seen by Jaward et al. [6,7]. In these four seawater samples a cycle was observed in the dissolved phase for the more volatile water soluble PCB congeners (Table S3). No cycle was observed for PAHs in the seawater samples. PCBs in the dissolved phase displayed the same diel cycle as the more volatile PCBs in the atmosphere, with the day time concentration being higher than the night time concentration by a factor of between $>1.5$ for PCB 22, 28, 52 and 118. The lack of replicates for water sampling is insufficient to decide whether this difference is statistically significant. However, it should be noted that this variation in dissolved phase PCB concentrations occurred in samples taken from water at $8 \mathrm{~m}$ depth. It is generally assumed that the surface waters are well mixed to about $20 \mathrm{~m}$ in tropical regions [1]. However, only the first few meters of the surface ocean are expected to interact with the atmosphere in the short-term and are believed to be near equilibrium conditions in this region $[18,19]$.

\subsection{Evaluation of Possible Ship-Borne Sources}

One hypothesis that may explain the diel variability of POP concentration in air is that the ship may act as a source of POPs to the local atmosphere. In principal the ship could contaminate the background air by (1) venting of in-ship air to the outside; (2) emissions from use/release on the ship; (3) simple temperature driven reversible deposition to/from the ship surface.

PCB levels measured in samples from the $R V$ Polarstern indicate that the ship is not a significant source [18]. $R V$ Polarstern has previously been used to measure ultra-low PCB concentrations in the Southern Ocean (e.g., $[15,16,19])$, and levels in air determined from the ship $\left(<10 \mathrm{pg} \cdot \mathrm{m}^{-3}\right)$ are very similar to land-based measurements at Saint Helena $\left(2-10 \mathrm{pg} \cdot \mathrm{m}^{-3}\right)$ [18] and to those reported by 
Jaward et al. [6] on board the RV Pelagia. The PCB congener profiles in air samples from Saint Helena are similar to those collected on the ship with the tri- $\mathrm{Cl}$ and tetra- $\mathrm{Cl}$ being the most abundant in the mixture. Additionally, the diel cycle was only seen in part of the ocean, whereas a ship contamination problem would be ubiquitous. These observations indicate that truly background air was sampled on the $R V$ Polarstern without any ship interference.

As for PAHs, ship sources of contamination are different from those of PCBs. They can be affected by stack emissions when the air has moved over the ship before reaching the sampler or the evaporation of diesel fuel on-board. Passive air samplers deployed at the front and at rear of the ship showed different PAH profiles with the more volatile dominating at the front and the heaviest at the back, which indicates a minimal contamination from ship's stack emissions at the sampling point [16].

Back trajectories showed that air arriving at the sampler on the ship had crossed the Atlantic Ocean for at least 7 days. These samples therefore represent "aged" background air at these remote locations. Samples where the diel cycle was observed (numbers 23-34 in Figure 2) were clearly oceanic samples. Air and water temperatures were in a narrow range between the equator and Cape Town $\left(18-26{ }^{\circ} \mathrm{C}\right)$ and varied by only $1-2{ }^{\circ} \mathrm{C}$ between day and night. The wind speed was quite stable averaging $7-9 \mathrm{~m} \cdot \mathrm{s}^{-1}$. For the majority of the samples where diel variability in PCB and PAH concentrations in air was observed, the atmospheric mixing height was stable and between 300 and $600 \mathrm{~m}$ (see back trajectory and atmospheric mixing height examples in the Supporting Information). The diel variability in compound concentrations was not accompanied by any systematic variability in mixing height.

Figure 2. Sampling locations and broad origin of the air masses of the cruise. Numbers in the Figure indicate station numbers of air. The red circle indicates the area of the Southern Ocean where the diel cycle was observed. On the right, simple conceptual diagram of the parameterization of the level III/IV mass balance model.

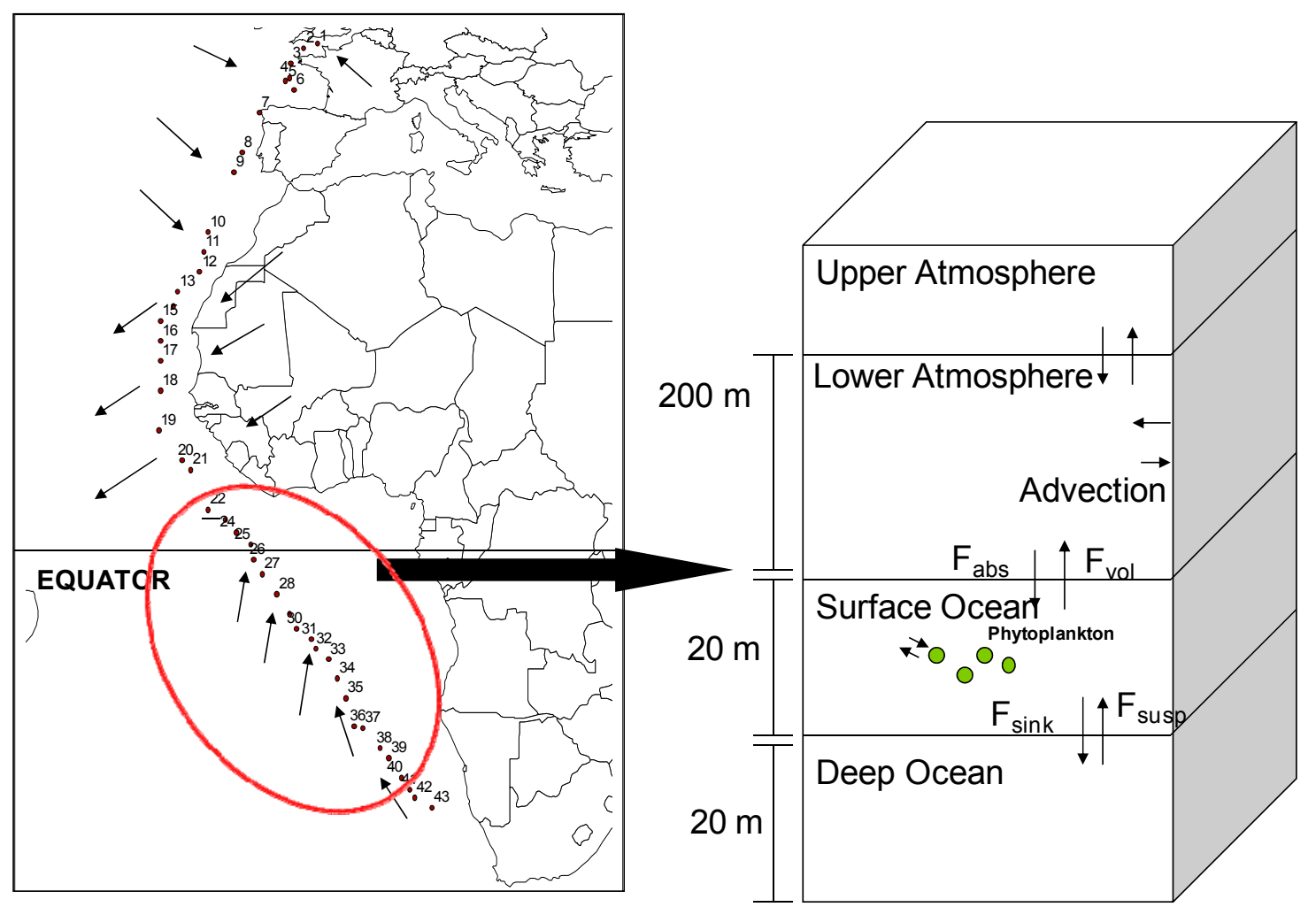




\subsection{Modeling Potential Atmospheric Controlling Factors of Air Concentrations}

We selected an existing fugacity-based model (BETR) that can be run for steady-state (Mackay Level III) or non-steady state (Mackay Level IV) scenarios [20]. This mass balance model was used to conduct bounding modeling scenarios that were designed to identify potential causes of the diel POPs cycle over the ocean. The model is described in detail in MacLeod et al. [17], who previously applied it to interpret diel variability in PCB concentrations measured in the field from several different studies using local data on temperature, wind speed, atmospheric mixing height and hydroxyl radical $(\mathrm{OH})$ concentrations. The model has also been extensively applied and evaluated for PCBs and other persistent, semi-volatile air pollutants over urban areas, and to calculate emission rates of chemicals from diffuse sources [21,22], and was earlier adapted to study drivers of variability of atmospheric levels of volatile and semi-volatile air pollutants during extreme weather events [23-26]. The model uses mass balance equations formulated using the fugacity approach [20]. Fugacity is a criterion of equilibrium, and thus comparing fugacities of chemical in two different model compartments indicates the direction of the thermodynamic gradient for diffusion of chemicals. We used partitioning properties for PCB 28 and PCB 153 from Schenker et al. [27], and did not correct the air-water partition coefficient for the effect of salt water. Reaction rates of PCB 28 and PCB 153 with $\mathrm{OH}$ radical in the atmosphere were extrapolated from data presented by Anderson and Hites [28]. The degradation half-lives of PCB 28 and PCB 153 in water were set at $5500 \mathrm{~h}$ and 55,000 h respectively, and degradation in water was not an important process in our dynamic model scenarios.

The version of the model applied in this study is a single region implementation of the Berkeley-Trent (BETR) contaminant fate modeling framework, that is described in detail elsewhere [17]. A schematic representation of the modified version of the model used in this study is presented in Figure 2. The model was parameterized to describe an atmospheric layer over two vertically segmented ocean water layers. The height of the atmosphere was set to $200 \mathrm{~m}$, which is typical of the low-end of the range of mixing heights determined in the NCEP analysis and is consistent with assumptions used in calculations presented in Jaward et al. [6], and the oceanic layers were each set to $20 \mathrm{~m}$ depth. The mixing layer depth (MLD) data from levitus climatology (http://www.nodc.noaa.gov/OC5/ pr_woa4.html) indicate that the MLD was in the range of 10-30 $\mathrm{m}$ in this region in this period for the year. Air-side and water-side diffusion mass transfer coefficients calculated for wind speeds observed during the cruise were used in the model. Concentrations of organic carbon in the ocean were set at $0.2 \mathrm{mg} \cdot \mathrm{L}^{-1}$, a value typical of the open ocean $[29,30]$. Calculations were performed considering a $100,000 \mathrm{~km}^{2}$ region around the sampling location and assuming an air residence time of $18 \mathrm{~h}$, which corresponds to an average wind speed of $5 \mathrm{~m} / \mathrm{s}$. PCB 28 was selected as a test case, and a constant background inflow concentration tuned to provide modeled air concentrations consistent with those measured during this cruise and that of Jaward et al. [6,7] was used as an input function.

When the model was applied to the data set of this study and the Jaward et al. [6,7] study, the changes in the four atmospheric variables could not explain the amplitude of the diel cycle of POPs in the atmosphere. This indicated that other factors may be important in controlling the gas-phase concentration in this region of the ocean which were not considered in this model. The same conclusions were reached earlier, when the $R V$ Pelagia dataset was discussed in the paper by Jaward et al. [6,7]. 


\subsection{Modeling the Influence of Biomass Variability in Seawater on the Diel Cycle of PCBs in} the Atmosphere

Jaward et al. [6] put forward the hypothesis that variability in organic carbon (OC) concentration in the surface ocean as a result of diel cycles in zooplankton migration, DOC cycle, and/or phytoplankton biomass turn-over might be responsible for the observed variability in air concentrations. We explored that hypothesis using our model by formulating a bounding scenario for variability of OC and two scenarios for chemical transport to the remote Atlantic Ocean. Our intention is to use our modeling as a screening tool to make a first evaluation of whether documented cycles in biomass $[29,30]$ could possibly account for the diel cycle in concentrations of POPs in air. In this scoping exercise, we have not made any effort to quantitatively model the biology involved in these processes, nor to account for spatial variability within the large area of the ocean described by our model. Our goal here is to evaluate alternative hypotheses and provide information that can guide further modeling or field studies.

Analysis of data collected during the cruise and air-parcel back trajectories indicated that temperature, wind speed and atmospheric mixing height were all approximately constant over the entire sampling period. In contrast, the $\mathrm{OC}$ content of ocean water and the $\mathrm{OH}$ radical concentration in air varied over a $24 \mathrm{~h}$ cycle during the cruise. We constructed a model scenario for variability in OC content in ocean water in which $\mathrm{OC}$ is 5 times higher than the long-term average from noon to midnight, and 5 times lower than the long-term average from midnight to noon (middle panel of Figure 3). This scenario represents an extreme case of possible variability due to the biological cycle [30]. Thus, our modeling is a bounding analysis of the possible influence of biomass variability on atmospheric levels of PCBs. In reality, OC content of surface oceans does not vary as much as in the model scenarios, but this model parameterization was used to represent the potential increase in sorbing capacity of chemical induced by both the increase in OC and the increase in surface area available to sorb POPs when phytoplankton is dividing and growing in the late afternoon. We also modeled diel variability in $\mathrm{OH}$ radical concentrations in the atmosphere as described earlier [17].

The model was run under two different scenarios for transport of PCB 28 and PCB 153 to the remote Atlantic Ocean. The two transport scenarios were selected to encompass situations in which the remote ocean acts as a net source or a net sink of POPs in the atmosphere. Both scenarios begin with a model spin-up in which concentrations of $\mathrm{OH}$ radicals in air and $\mathrm{OC}$ in ocean water are held constant at average values, and the atmosphere and the ocean come to steady-state with a constant inflowing concentration of PCBs in the atmosphere. In the first, "constant inflow scenario" the concentration of PCBs entering the model domain in the atmosphere remains constant, and concentrations of $\mathrm{OH}$ radicals and $\mathrm{OC}$ in ocean are varied. In this scenario the ocean acts as a net sink for PCBs. In the second scenario the concentration of PCBs entering the model domain in the atmosphere is reduced by a factor of 10, "constant inflow declined by factor of 10" scenario at same time that concentrations of $\mathrm{OH}$ radicals in air and $\mathrm{OC}$ and ocean begin to vary. This scenario represents a case where the ocean may become a net source of PCBs to the atmosphere.

In all model scenarios the effect of variability in $\mathrm{OH}$ radical concentrations on PCBs is negligible. In the constant inflow scenario, model results indicate that net air-water exchange is too low for variability in ocean conditions to be inducing the observed variability in air concentrations (Red lines in Figure 3). In the "constant inflow declined by factor of 10" scenario, variability in concentrations of 
PCB 28 in air of about a factor of 2 are predicted by the model, which is consistent with observations from the cruises for lighter PCBs (Figure 3, blue line in the top panel). For PCB 153, the model predicts very low variability in the lower air concentration (Figure 3, blue line in the bottom panel). For the heavier PCB 153 congener, the fugacity in the lower air compartment rapidly approaches, but never crosses below the fugacity in ocean water, and the ocean does not become a net source to atmosphere. Thus, in our model scenario with a "clean" air mass moving over a relatively contaminated ocean the model qualitatively reproduces the field observations of diel variability for low chlorinated PCB congeners but not high chlorinated congeners.

Figure 3. Modeled variability in atmospheric concentrations of PCB 28 (top panel), concentrations of organic carbon (OC) variation by a factor of 5 in the ocean mixed layer over a $24 \mathrm{~h}$ period (middle panel) and PCB 153 (bottom panel) in a remote region of the Atlantic Ocean under two alternative model scenarios.. In the "Constant Inflow Scenario", atmospheric concentrations of the two PCBs entering the remote region are constant. In the "Inflow Declines by Factor 10" scenario a "clean" air mass moves into the remote region that was previously at steady-state with an air mass with 10 times higher concentrations of both PCBs. The simulation time begins at midnight and covers a $96 \mathrm{~h}$ period.

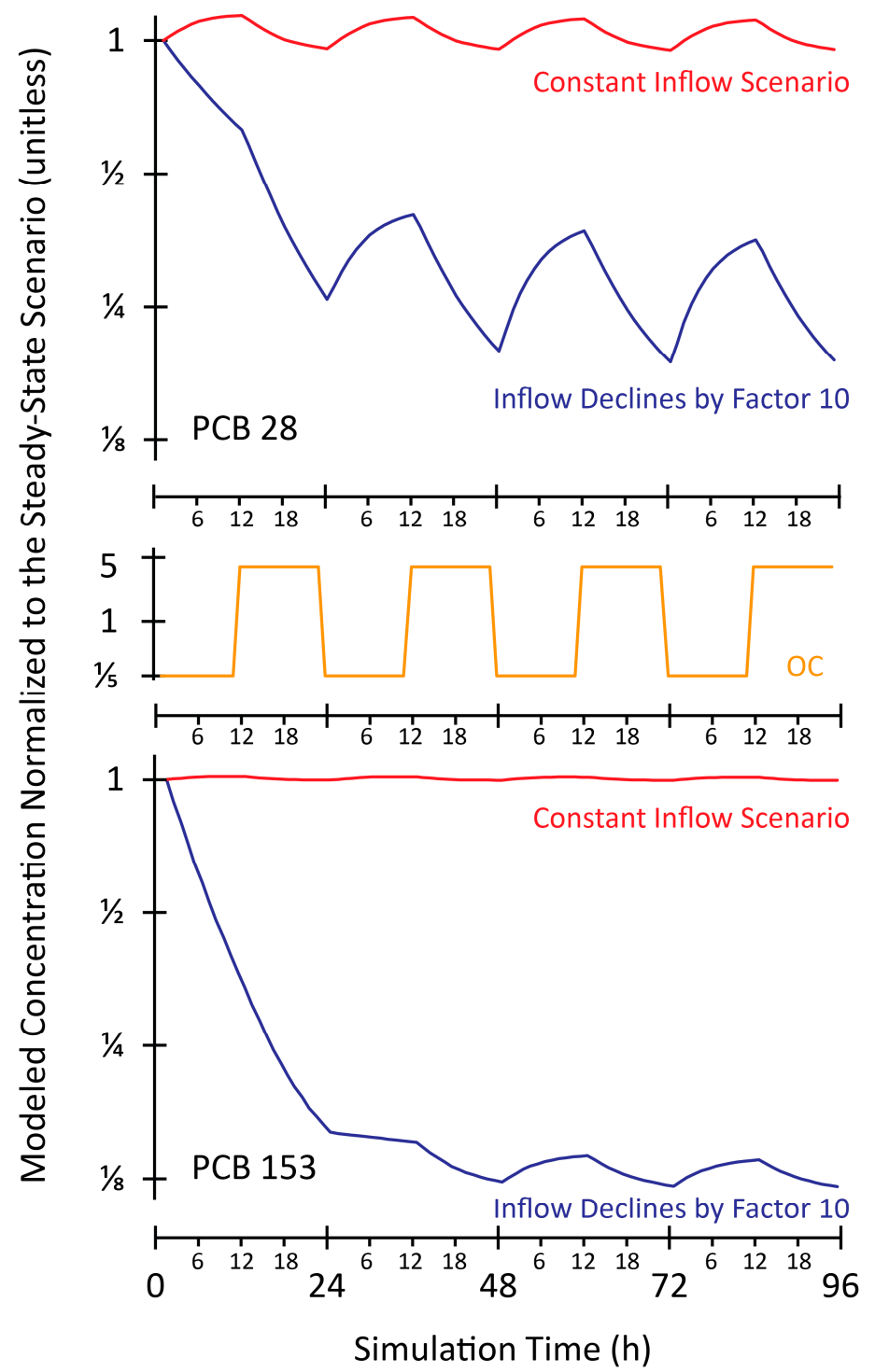


In our "constant inflow declined by factor of 10" model scenario the fugacity of PCB 28 in surface ocean water varies by a factor of 15 over a diel period, and that variability drives the factor of 2 variability in atmospheric concentrations. The model results are highly sensitive to assumptions about atmospheric dynamics and the kinetics of transfer between the atmosphere and ocean. We assumed a $200 \mathrm{~m}$ atmospheric mixing height, which may not be appropriate if a concentration gradient exists near the ocean surface. Under a lower "effective mixing height" assumption, lower OC variability would induce a factor of 2 variability in concentrations of PCB 28 in air. Under extreme assumptions of fast air-ocean exchange kinetics there would be near equilibrium partitioning, and variability of only a little more than a factor of 2 in the fugacity capacity of the ocean water compartment could induce a factor of 2 variability in atmospheric concentrations of either PCB 28 or PCB 153.

It is difficult with the current knowledge of POP cycling to identify potential process(es) that could induce a variability by a factor of $2-15$ in surface water fugacities. One driver could be a diel cycle in the properties, composition and thus POP enrichment of the surface microlayer, another could be an important influence of zooplankton mediated transport. Zooplankton migrates to surface waters at night, which could induce a higher fugacity capacity of the surface ocean. Recently, it has been shown that zooplankton takes up and degrades PAHs efficiently and with short response times [31]. Presumably, PCBs are not degraded by zooplankton and marine bacteria, which could be a factor driving the observed differences between these two classes of pollutants. Finally, the variability in phytoplankton cell surface has also the potential to affect the sorbing capacity of surface waters. Still, there is the need for further research to elucidate the dominant drivers of air-water exchange, which certainly may have a very important role of long-range transport of POPs.

\section{Conclusions}

The data presented here are consistent with a close coupling of air-open ocean concentrations, which has important implications for future rates of POP removal from the global recyclable pool and atmospheric concentrations time trends. The Level III/IV mass balance model suggests that the diel variability of lighter PCBs and PAHs may be a complex process that involves not only physical parameters (i.e., atmospheric mixing height, $\mathrm{OH}$ radical degradation, temperature or the wind speed) but also biogeochemical variables, such as phytoplankton biological properties and cycles. We provide here a first modeling framework and some bounding scenarios that explore factors that might drive the observed diurnal variability. Our modeling could qualitatively reproduce the observed diurnal variability for PCB 28 when concentrations in air are low compared to a steady-state situation. These conditions produce daytime volatilization and nighttime deposition of PCB 28 and no diel signal for PCB 153, which is consistent with the field data. In a more general framework, the potential influence of the diurnal variability of atmospheric concentrations of POPs in the establishment of representative time trends under current monitoring programs should be taken into account. Given our poor understanding of processes driving diel variability of POPs, a minimum of $24 \mathrm{~h}$ integrated air samples are recommended to obtain representative concentrations for long-term monitoring purposes and to draw conclusions on the implementation and effectiveness of international regulations on POPs, such as the Stockholm Convention. 


\section{Acknowledgments}

The authors would like to thank the crew on the $R V$ Polarstern as well as the scientists for their excellent support and cooperation. We would like to thank Armando Caba and Annika Jahnke for their assistance during sampling on the ship and Kerstin Heymann for pigment HPLC analysis. We gratefully acknowledge financial support from the Department of the Environment, Food and Rural Affairs (DEFRA) on POPs at Lancaster University.

\section{Author Contributions}

Sampling and sample processing in the laboratory: Rosalinda Gioia, Luca Nizzetto, Rainer Lohmann, Kevin C. Jones. Modeling calculations: Matthew MacLeod, Rosalinda Gioia. Modeling the influence of seawater biomass on the diel cycle: Mathew MacLeod, Jordi Dachs, Rosalinda Gioia, Luca Nizzetto, Kevin C Jones. Wrote the paper: Rosalinda Gioia, Matthew MacLeod, Javier Castro-Jimenez.

\section{Conflicts of Interest}

The authors declare no conflict of interest.

\section{References}

1. Jurado, E.; Lohmann, R.; Meijer, S.; Jones, K.C.; Dachs, J. Latitudinal and seasonal capacity of surface oceans as a reservoir of polychlorinated biphenyls. Environ. Pollut. 2004, 128, 149-162.

2. Jurado, E.; Jaward, F.; Lohmann, R.; Jones, K.C.; Simó, R.; Dachs, J. Wet deposition of persistent organic pollutants to the global oceans. Environ. Sci. Technol. 2005, 39, 2426-2435.

3. Dachs, J.; Eisenreich, S.J.; Baker, J.E.; Ko, F.-C.; Jeremiason, J.D. Coupling of phytoplankton uptake and air-water exchange of persistent organic pollutants. Environ. Sci. Technol. 1999, 33, 3653-3660.

4. Dachs, J.; Lohmann, R.; Ockenden, W.; Mejanelle, L.; Eisenreich, S.J.; Jones, K.C. Oceanic biogeochemical controls on global dynamics of persistent organic pollutants. Environ. Sci. Technol. 2002, 36, 4229-4237.

5. Jurado, E.; Dachs, J. Seasonality in the "grasshopping" and atmospheric residence times of persistent organic pollutants over the oceans. Geophys. Res. Lett. 2008, doi:10.1029/2008GL034698.

6. Jaward, M.F.; Barber, J.L.; Booij, K.; Dachs, J.; Lohmann, R.; Jones, K.C. Evidence for dynamic air-water coupling and cycling of persistent organic pollutants over open Atlantic Ocean. Environ. Sci. Technol. 2004, 38, 2617-2625.

7. Jaward, F.M.; Barber, J.L.; Booij, K.; Jones, K.C. Spatial distribution of atmospheric PAHs and PCNs along a north-south Atlantic transect. Environ. Pollut. 2004, 132, 173-181.

8. Hornbuckle, K.C.; Eisenreich, S.J. Dynamics of gaseous semivolatile organic compounds in a terrestrial ecosystem-effects of diurnal and seasonal climate variations. Atmos. Environ. 1996, 30, 3935-3945.

9. Wallace, J.C.; Hites, R.A. Diurnal variations in atmospheric concentrations of polychlorinated biphenyls and endosulfan: Implications for sampling protocols. Environ. Sci. Technol. 1996, 30, 444-446. 
10. Lee, R.G.M.; Hung, H.; Mackay, D.; Jones, C.K. Measurement and modeling of the diurnal cycling of atmospheric PCBs and PAHs. Environ. Sci. Technol. 1998, 32, 2172-2179.

11. Gouin, T.; Thomas, G.O.; Cousins, I.; Barber, J.; Mackay, D.; Jones, K.C. Air-surface exchange of polybrominated diphenyl ethers and polychlorinated biphenyls. Environ. Sci. Technol. 2002, $38,1426-1434$.

12. Totten, L.A.; Eisenreich, S.J.; Brunciak, P.A. Evidence for destruction of PCBs by the OH radical in urban atmospheres. Chemosphere 2002, 47, 735-746.

13. Lohmann, R.; Brunciak, P.A.; Dachs, J.; Gigliotti, C.L.; Nelson, E.; van Ry, D.; Glenn, T.; Eisenreich, S.J.; Jones, J.L.; Jones, K.C. Processes controlling diurnal variations of PCDD/Fs in the New Jersey coastal atmosphere. Atmos. Environ. 2003, 37, 959-969.

14. Sofuoglu, A.; Cetin, E.; Bozacioglu, S.S.; Sener, G.D.; Odabasi, M. Short-term variation in ambient concentrations and gas/particle partitioning of organochlorine pesticides in Izmir, Turkey. Atmos. Environ. 2004, 38, 4483-4493.

15. Gioia, R.; Nizzetto, L.; Lohmann, R.; Dachs, J.; Jones, K.C. Polychlorinated biphenyls (PCBs) in air and seawater of the Atlantic Ocean. Environ. Sci. Technol. 2008, 42, 1416-1422.

16. Nizzetto, L.; Lohmann, R.; Gioia, R.; Jahnke, A.; Temme, C.; di Guardo, A.; Jones, K.C. PAHs in air and seawater along a North-South Atlantic transect: Trends and controlling processes. Environ. Sci. Technol. 2008, 42, 1580-1585.

17. MacLeod, M.; Scheringer, M.; Podey, H.; Jones, K.C.; Hungerbühler, K. The origin and significance of short-term variability of semi-volatile contaminants in air. Environ. Sci. Technol. 2007, 41, 3249-3253.

18. Gioia, R.; Lohmann, R.; Nizzetto, L.; Dachs, J.; Temme, C.; Jones, C.K. Sampling POPs in the oceanic remote locations: Dealing with ship-based contamination. In Chemical Pollution and Environmental Changes; Universal Academy Press, INC.: Tokyo, Japan, 2007; pp. 19-22.

19. Gioia, R.; Lohmann, R.; Dachs, J.; Temme, C.; Lakaschus, S.; Schulz-Bull, D.; Hand, I.; Jones, K.C. Polychlorinated biphenyls in air and seawater of the North Atlantic and the Arctic Ocean. J. Geophys. Res. 2008, doi:10.1029/2007JD009750.

20. Mackay, D. Multimedia Enviornmnetal Models: The Fugacity Approach, 2nd ed.; CRC Press: Cleveland, OH, USA, 2006.

21. Bogdal, C.; Wang, Z.; Buser, A.M.; Scheringer, M.; Gerecke, A.C.; Schmid, P.; Müller, C.E.; MacLeod, M.; Hungerbühler, K. Emissions of Polybrominated Diphenyl Ethers (PBDEs) in Zurich, Switzerland, determined by a combination of measurements and modeling. Chemosphere 2014, in press.

22. Buser, A.M.; Bogdal, C.; Bogdal, C.; Scheringer, M. Emissions of decamethylcyclopentasiloxane from Chicago. Chemosphere 2014, 107, 473-475.

23. Bogdal, C.; Müller, C.E.; Buser, A.M.; Wang, Z.; Scheringer, M.; Gerecke, A.C.; Schmid, P.; Zennegg, M.; MacLeod, M.; Hungerbühler, K. Emissions of polychlorinated biphenyls, polychlorinated dibenzo-p-dioxins, and polychlorinated dibenzofurans during 2010 and 2011 in Zurich, Switzerland. Environ. Sci. Technol. 2014, 48, 482-490.

24. Wang, Z.; Scheringer, M.; MacLeod, M.; Bogdal, C.; Müller, C.E.; Gerecke, A.C.; MacLeod, M.; Hungerbühler, K. Atmospheric fate of poly-and perfluorinated alkyl substances (PFASs): II. Emission dource strentgh in summer in Zurich, Switzerland. Environ. Pollut. 2012, 169, 204-209. 
25. Gasic, B.; MacLeod M.; Klanova, J.; Scheringer, M.; Ilic, P.; Lammel, G.; Pajovic, A.; Breivik, K.; Holoubek, I.; Hungerbühler, K. Quantification of sources of PCBs to the atmosphere in urban areas: A comparison of cities in North America, Western Europe and former Yugoslavia. Environ. Pollut. 2010, 158, 3230-3235.

26. Gasic, B.; MacLeod, M.; Klanova, J.; Scheringer, M.; Hungerbühler, K. Assessing the impact of weather events at mid-latitudes on the atmospheric transport of chemical pollutants using a 2-dimensional multimedia meteorological model. Atmos. Enviorn. 2010, 44, 4489-4496.

27. Schenker, U.; MacLeod, M.; Scheringer, M.; Hungerbühler,K. Improving data quality for enviornmnetal fate models: A least-squares adjustment procedure for harmonizing physico-chemical properties of organic compounds. Environ. Sci. Technol. 2005, 39, 8434-8441.

28. Anderson, P.N.; Hites, R. OH Radicals Reactions: The major removal pathway for polychlorinated biphenyls from teh atmosphere. Environ. Sci. Technol. 1996, 30, 1756-1763.

29. Binder, B.J.; du Rand, M.D. Diel cycles in surface waters of the equatorial Pacific. Deep-Sea Res. II 2002, 49, 2601-2617.

30. Walsh, I.D.; Chung, S.P.; Richardson, M.J.; Gardner, W.D. The diel cycle in the integrated particle load in the equatorial Pacific: A comparison with primary production. Deep-Sea Res. 1995, 42, 465-477.

31. Berrojalbiz, N.; Lacorte, S.; Calbet, A.; Saiz, E.; Barata, C.; Dachs, J. Accumulation and cycling of polycyclic aromatic hydrocarbons in zooplankton. Environ. Sci. Technol. 2009, 43, 2295-2301.

(C) 2014 by the authors; licensee MDPI, Basel, Switzerland. This article is an open access article distributed under the terms and conditions of the Creative Commons Attribution license (http://creativecommons.org/licenses/by/3.0/). 